This item was submitted to Loughborough's Research Repository by the author.

Items in Figshare are protected by copyright, with all rights reserved, unless otherwise indicated.

\title{
Assessing hydration status and reported beverage intake in the workplace
}

PLEASE CITE THE PUBLISHED VERSION

http://dx.doi.org/10.1177/1559827614523706

\section{PUBLISHER}

Sage Publications (@ 2014 The Authors)

\section{VERSION}

AM (Accepted Manuscript)

\section{PUBLISHER STATEMENT}

This work is made available according to the conditions of the Creative Commons Attribution-NonCommercialNoDerivatives 4.0 International (CC BY-NC-ND 4.0) licence. Full details of this licence are available at: https://creativecommons.org/licenses/by-nc-nd/4.0/

\section{LICENCE}

CC BY-NC-ND 4.0

\section{REPOSITORY RECORD}

Mears, Stephen A., and Susan M. Shirreffs. 2019. "Assessing Hydration Status and Reported Beverage Intake in the Workplace". figshare. https://hdl.handle.net/2134/20185. 
1 Title Page

2

3 Assessing hydration status and reported beverage intake in the workplace

4

5 Stephen A Mears, PhD, Susan M Shirreffs, PhD

6 School of Sport, Exercise and Health Sciences, Loughborough University, Loughborough,

7 LE11 3TU, UK

8 S.A.Mears@lboro.ac.uk +44(0)1509 226371

$9 \quad$ Susan.M.Shirreffs@gsk.com +44 (0)1509 226371

10

11 Corresponding Author

12 Stephen Mears

13 School of Sport, Exercise and Health Sciences, Loughborough University, Loughborough,

14 LE11 3TU, UK

15 Telephone: +44 (0)1509226371

16 Fax: +44 (0)1509 226301

17 Email: S.A.Mears@lboro.ac.uk

18

19 Running title: Hydration status in the workplace

20

21 Key words: hydration, workplace, water intake 
23 Abstract

25 The aim was to examine the hydration status of adults working in different jobs at the 26 beginning and end of a shift and their reported water intake. 156 subjects (89 males, 67 27 females) were recruited from workplaces within the local area (students, teachers, security, 28 office, firefighters catering). A urine sample was provided at the start and end of the shift 29 and analysed for osmolality ( $\mathrm{U}_{\text {osm }}$ ), specific gravity (USG) and sodium and potassium 30 concentrations. Euhydration was considered $\mathrm{U}_{\mathrm{osm}}<700 \mathrm{mOsmol} / \mathrm{kg}$ or $\mathrm{USG}<1.020$. At the 31 end of the shift subjects were asked to report all water intake from beverages during the shift. 32 Females had lower $U_{\text {osm }}$ than males at the start (656 (range 85-970) v 738 (range 164-1090) $33 \mathrm{mOsmol} / \mathrm{kg}$ ) and end (461 (range 105-1014) v 642 (range 130-1056) mOsmol/kg; $P<0.05$ ) of 34 their working day. 52\% of individuals who appeared hypohydrated at the start of the shift 35 were also hypohydrated at the end. Reported water intake from beverages was greater in 36 males compared to females (1.2 (range 0.0-3.3) v 0.7(range 0.0-2.0) litres respectively; $37 P<0.0001)$. In conclusion, a large proportion of subjects exhibited urine values indicating 38 hypohydration with many remaining in a state of hypohydration at the end of the shift. 
Mears 3

40 Key Words

41

42 hydration, workplace, water intake, classroom

43 
Introduction

The importance of monitoring hydration in the workplace is important from a health and a functional point of view as well as providing indication of drinking behaviours. Previous studies examining hydration status in the workplace have focussed on workers in hot and 50 humid conditions performing physical activity ${ }^{(1,2)}$ and those wearing personal protective equipment ${ }^{(3,4)}$. These studies have tended to focus on extreme situations and environmental conditions which may not be applicable to those who work in temperate conditions performing less strenuous activity without protective equipment. In many work places, environmental conditions are often controlled by air conditioning and heating systems and many workers may remain seated at a desk for a large portion of the shift.

When hydration status has been examined in the workplace, many workers have arrived already dehydrated ${ }^{(2)}$. In this study by Brake and Bates ${ }^{(2)}$ it was found that around $60 \%$ of underground miners reported to work in a dehydrated state and hydration status did not improve over the course of the shift. With the majority of workers arriving already dehydrated they may be required to consume extra water in addition to normal consumption in order to return to a euhydrated state.

63

64 The reasons why individuals chose to drink or not to drink in certain scenarios can be

65 assessed by the consideration of drinking influences and access to beverages. Understanding this may help prevent hypohydration and possible subsequent impairment of performance.

67 For example anecdotal evidence from questionnaires has shown that individuals restricted 68 water intake if toilet facilities were not available ${ }^{(5)}$. Limited access to toilet facilities (e.g. 
when driving or when a teacher is looking after a class) may have had an impact on the amount of subsequent water consumed during the shift, and may have contributed to any dehydration that may have occurred.

Typically euhydration has been considered when USG values are below 1.020 and urine osmolality is below $700 \mathrm{mOsmol} / \mathrm{kg}^{(6)}$. These values outlined by Sawka et al. ${ }^{(6)}$ in the American College of Sports Medicine (ACSM) position stand, provided a guideline for selfassessment and were derived from previous studies ${ }^{(7,8)}$. The guidelines provide an approximate classification of whether an individual is euhydrated but do not provide an indication of hyperhydration or to the severity of dehydration.

From a health standpoint, reduced habitual water intake has been associated with colon cancer $^{(9)}$ and cancer of the bladder ${ }^{(10)}$. In the workplace, particularly if water intake or access to beverages is restricted due to the line of work or facilities, it is possible workers may become more at risk to these health issues.

In addition to maintenance of health, one of the main reasons for examining hydration status in the workplace is the associated decline in cognitive function with dehydration. The effect of dehydration has been studied in a variety of situations relating to cognitive performance, however the concluding effect is often varied ${ }^{(11,12)}$. As part of a review, Lieberman ${ }^{(11)}$ assessed the effect of water restriction alone on cognitive performance and decided that there was not enough evidence to provide a definitive conclusion. However, in the review by Grandjean and Grandjean ${ }^{(12)}$, they concluded that a body mass loss of greater than $2 \%$ caused by dehydration through water restriction, exercise and/or heat can have a negative impact on cognitive performance. In the workplace, a reduction in cognitive performance may reduce 
94 quality of work, productivity and decision making, thereby making workers ineffectual.

95 Dehydration of between 2 and $4 \%$ body mass loss has been shown to reduce short-term 96 memory, visual motor tracking, arithmetic efficiency and attention ${ }^{(13)}$ and decrease

97 perspective discrimination and psycho-motor skills ${ }^{(14)}$. Studies examining the relationship

98 between dehydration and cognitive performance have tended to elicit dehydration through 99 exercise or heat and exercise $\mathrm{e}^{(13,14)}$, and therefore not directly applicable to situations 100 commonly experienced in many workplaces.

101

102 Assessing water intake behaviours during a shift and hydration status of workers at the start 103 and end of their shift may help identify those who are dehydrated and hyperhydrated whilst 104 also identifying ways to prevent it from occurring. Therefore, the primary aim of this study 105 was to examine the hydration status of different work groups at the beginning and end of a 106 shift (approximately 8 hours). A secondary aim was to examine the influences on water 107 intake (e.g. access to water, water cooler towers, breaks, access to toilet facilities etc.) and 108 behaviours between the groups monitored and examine whether this could affect or influence 109 observed hydration status. 
111 Experimental methods

112

113 Subjects

114156 subjects (32 (range 19-63) years, 1.74 (SD 0.10) m, 77.6 (SD 15.3) kg) comprising of 89

115 males and 67 females were recruited from the local area. Subjects were research students $(n$

116 33), classroom taught students ( $n$ 24), teachers ( $n$ 31), security staff ( $n$ 15), firefighters ( $n$ 22),

117 office workers (n 15) and catering staff (chefs and kitchen assistants) ( $n$ 16). Subjective

118 characteristics for each group are displayed in Table 1. This study was conducted according

119 to the guidelines laid down in the Declaration of Helsinki and all procedures involving human

120 subjects were approved by the Loughborough University Ethics Committee. Written

121 informed consent was obtained from all subjects.

122

123 Groups

124 Each group is described below with a brief description of a typical working day and any

125 breaks that were allowed for each group of subjects. Any major barriers to water intake are

126 also noted.

127 Research - University $\mathrm{PhD}$ and research students primarily based in an office environment

128 but with visits to laboratory for short periods of experimental work. No restriction on

129 frequency and duration of break times and were able to eat and drink freely as they worked.

130 Classroom taught students - University MSc students who participated in laboratory classes

131 all day and therefore considered typical of a laboratory worker with restrictions on food and

132 drink access. Food and water intake banned in the laboratory so subjects had to leave the

133 laboratory to eat and drink. One hour break at lunch.

134 Teachers - Taught classes (secondary school) for at least five hours per day with a small

135 break of approximately 5 minutes after each one hour lesson. One hour for lunch break and a 
13620 minute break at around 10am. Unable to leave the classroom and use toilet facilities

137 whilst teaching classes. Unable to eat during classes but were able to consume their own 138 drinks.

139 Security - University security staff working a variety of shift patterns including night shifts.

140 A 15 minute break before and after a 30 minute lunch/dinner break. Staff patrolled the 141 university on foot, bike and in motorised vehicles and were able to drink freely during the 142 shift when time permitted.

143 Firefighters - Day ( $n$ 17) and night ( $n$ 5) shifts observed. Staff performed maintenance and 144 practice drills throughout the day as well as having a physical activity session involving 145 strength and aerobic activity in the onsite gym. Physical activity and therefore sweat losses 146 were not recorded so that additional measures did not impact and influence a typical day. 147 Average number of call outs was three per day. Were able to eat and drink freely when not 148 performing drills or on call outs, when there was limited access to water.

149 Office - Staff were sat at computers throughout the duration of the day, two small 15 minute 150 breaks in the morning and afternoon and a 30 minute lunch break. Were able to eat and drink 151 freely whilst working.

152 Catering - Kitchen staff and chefs at university canteen. On feet throughout the majority of 153 the shift, with a large portion of work time (exact time unknown) spent in the kitchen 154 preparing food. Two 15 minute breaks and a 30 minute break for lunch. Were able to drink, 155 outside of scheduled break times, if time permitted.

157 Procedure

158 Subjects arrived at their place of work immediately prior to their shift and were asked to sign 159 an informed consent form, complete a $100 \mathrm{~mm}$ visual analogue subjective feelings 160 questionnaire comprising of six questions relating to thirst $(0=$ not at all thirsty, $100=$ very 
161 thirsty), mouth dryness $(0=$ not at all dry, $100=$ very dry $)$, hunger $(0=$ not at all hungry, $100=$ very hungry), tiredness $(0=$ not at all tired, $100=$ very tired $)$, concentration $(0=$ not very well, $100=$ very well $)$ and energy ( $0=$ no energy, $100=$ lots of energy) and a small questionnaire relating to their water intake patterns during a typical shift. The questionnaire asked about access to drinks, any influences on drinking, typical water consumption and whether they experienced thirst and changes in concentration during a shift. They then provided a urine sample, before height and body mass were measured to the nearest 10 g (Adam CFW-150, Milton Keynes, UK) whilst wearing loose fitting clothing (one layer) and without shoes. The urine sample may not have been the first void of the day but the aim of the study was to examine hydration on arrival at the workplace. Subjects were then asked to complete their work shift as normal. On completion of the shift subjects provided a urine sample. Body mass was measured but not reported. Changes in body mass could not be accurately related to change in hydration status due to not measuring accurately food and drink intake, sweat losses, urine output and excretion losses. It was felt that these measures would impact on the "typical day". They were asked to fill in the same subjective feelings questionnaire and a small questionnaire relating to their water intake during the shift. Questions related to access to drinks during the shift, how much they consumed, whether they experience a feeling of thirst and if so did they drink to alleviate this? Reported water intake was then presented as the water component of all drinks reportedly consumed. They were asked to rate their

180 concentration at the start, middle and end of the shift using a $100 \mathrm{~mm}$ visual analogue scale 181 and whether they felt they remained hydrated throughout the duration of the shift. Subjects were then free to leave. Ambient temperature and relative humidity was measured at the start and end of each shift both inside and outside the place of work (RH85 Digital ThermoHygrometer; Omega, Manchester, UK). The duration of each shift was based on a typical 
185 eight hour working day. To participate, all subjects must have completed a shift of at least

186 seven hours. All subjects completed this and none were excluded.

187

188 Sample analysis.

189 Urine samples were analysed for osmolality by freezing point depression (Gonotec Osmomat

190 auto Cryoscopic Osmometer; Gonotec, Berlin, Germany), specific gravity by refractometry

191 (Digit-012, Ceti, Belgium) and colour $^{(7)}$. Urine sodium and potassium concentrations were

192 measured by flame photometry (Corning Clinical Flame Photometer 410C; Corning Ltd.,

193 Halstead, Essex, UK). All samples were analysed in duplicate and a mean of the duplicate

194 was used.

195

196 Statistical analysis

197 All data was checked for normality using the Kolmogorov-Smirnov test if the data set was 198 large $(n>30)$ and the Shapiro-Wilk test if the data was less than $n=30$. One-way ANOVA and

199 Kruskal-Wallis tests were used for parametric and non-parametric data respectively to 200 identify differences between groups. Independent sample t-tests and Mann-Whitney tests 201 were subsequently performed as post-hoc analysis when significant differences were 202 observed and also to compare between start and end values within each population. Linear 203 regression was used to identify relationships. A significance value of $P<0.05$ was used. 204 Parametric data is expressed as mean (SD) and non parametric data expressed as median 205 (range). 
Results

208

209

Environmental conditions

210

Inside the places of work at the start of the shift, environmental conditions were 19.6 (SD

1.6) ${ }^{\circ} \mathrm{C}$ and $41.9 \%$ (range $27.8-55.5 \%$ ) relative humidity. At the end of the shift, temperature

212 was 20.5 (SD 1.0) ${ }^{\circ} \mathrm{C}$ and relative humidity was $41.7 \%$ (range 17.0-49.5\%). Outside conditions were 8.7 (SD 3.6) ${ }^{\circ} \mathrm{C}$ and 60.1 (SD 14.7) \% at the start and 9.5 (SD 4.1) ${ }^{\circ} \mathrm{C}$ and 56.0 (SD 14.3) \% at the end of the shift. Environmental conditions for each group presented in Table 2.

217 Pre-shift questionnaire

$21898 \%$ ( $n$ 153) of subjects had access to drinks during the course of their shift. When asked

219 about barriers to drinking during their shift, 67\% reported perceived influences on drinking 220 behaviour including sensations of thirst and mouth dryness, a lack of toilet facilities, timings 221 of breaks, remembering to drink and access to drinks in particular environments (e.g. on call 222 or in a laboratory). During a normal shift males reported (through cups and volumes) 223 consuming more water than females (1.0 (range 0.2-4.2) litres v 0.9 (range 0.1-2.0) litres) $224(P<0.0001)$. Typical reported water intake by classroom taught students $(0.6$ (range 0.1-1.5) 225 litres), teachers (0.6 (range 0.2-3.0) litres), security (1.0 (range 0.4-1.5) litres), catering (1.0 226 (range $0.5-2.0)$ litres) and office groups (1.0 (range $0.3-2.5)$ litres) was similar $(P>0.05)$, 227 whilst greater water intake was typically reported to be consumed in the research group (1.0 228 (range 0.4-3.0) litres) compared to the teachers group $(P<0.0001)$. The firefighters $(2.5$ 229 (range 1.0-4.2) litres) reported normally consuming more water than all other groups during a 230 typical shift $(P<0.0001)$. During a typical shift $56 \%$ of subjects reported normally 
experienced a sensation of thirst and $45 \%$ felt, during a normal shift, their concentration was affected if they did not drink enough water.

233

\section{General results}

235 For the population as a whole, lower urine osmolality and specific gravity values were 236 measured at the end of the shift (Table 3), whilst females arrived and left work with lower urine osmolality and specific gravity values $(P<0.05)$. Reported sensations of tiredness and hunger were higher at the end of the shift in the whole population, whilst reported sensations of concentration and energy were lower $(P<0.05)$ (Table 3). Sensations of thirst were similar

240 for the whole population $(P>0.05)$ but greater in females at the end of the shift compared to

241 the start $(P<0.05)$ (Table 3). There was large variation in individual start and end values of urine osmolality and USG for males and females with no clear patterns or trends emerging from the data (Fig 1). Subjects were classed as euhydrated if urine osmolality was less than

$244700 \mathrm{mOsmol} / \mathrm{kg}$ or urine specific gravity was less than $1.020^{(6)}$. Hypohydration was classed 245 as urine values above these values. Out of 156 subjects, 54\% started the shift with a urine osmolality representing hypohydration, with 35\% ending the shift with urine osmolality values considered hypohydrated (Table 4). 64\% of males started the shift hypohydrated compared to $42 \%$ of females. The research and firefighters group had the greatest proportion of subjects starting the shift in a hypohydrated state.

251 Group comparison

252 Between groups

253 USG values at the start of the shift in the research and firefighter group were greater than the 254 office, teachers and catering groups and were greater than end of shift values $(P<0.05)$ (Fig. 2). Urine osmolality values showed a similar pattern except start values for the research and 
256 firefighters group were also greater than the classroom taught students group and the

257 firefighters group were not greater than the start values in the catering group (Fig. 2). Urine

258 sodium concentrations were greater in the security group at the start of the shift compared to

259 the classroom taught students and teachers group and at the end of the shift compared to the

260 research, classroom taught students, teachers, firefighters and office groups $(P<0.05)$ (Fig. 2).

261 Urine potassium concentrations were lower at the end of the shift compared to the start in the 262 research group $(P<0.05)$ (Fig. 2).

263

264 Urine colour for males at the end of the shift was lower in the research group (2 (range 1-6))

265 compared to the classroom taught students group (4 (range 3-7)), security group (4 (range 1-

266 6)) and the catering group (5 (range 3-6)) $(P<0.05)$. Classroom taught students had greater

267 values of urine colour compared to teachers (2 (range 1-5)) but lower values than catering $268 \operatorname{staff}(P<0.05)$.

269

270 Urine sodium concentrations at the end of the shift for males were higher in the security group (145 (SD 39) mmol/l) compared to the researchers (105 (SD 43) mmol/l), classroom taught students students (93 (SD 45) mmol/l), teachers (91 (SD 47) mmol/l), firefighters (99 (SD 43) mmol/l) and office staff (83 (SD 41) mmol/l) $(P<0.05)$. Catering staff (151 (SD 30) $\mathrm{mmol} / \mathrm{l}$ ) had greater sodium concentrations at the end of the shift compared to classroom taught students, teachers and firefighters $(P<0.05)$.

277 Females in the classroom taught students group had higher end of shift concentrations for urine potassium concentrations (110 (SD 33) mmol/l) compared to researchers (73 (SD 34) mmol/l), teachers (79 (SD 40) mmol/l) and security guards (58 (SD 17) mmol/l) $(P<0.05)$. 
280 Catering staff females had higher urine potassium concentrations at the end of the shift (100

281 (SD 24) mmol/l) compared to the researchers and security guards $(P<0.05)$.

282

283 Within groups

284 In the research group a reduction from the start to the end of shift values for USG, osmolality 285 and potassium concentrations occurred for the whole group and within males and females $286(P<0.05)$. Urine colour was lower at the end of the shift in the whole research group and for 287 male researchers (both 4 (range 1-6) v 2 (range 1-6)) whilst comparing the research group as a whole revealed a reduction in energy levels at the end of the shift (63 (SD 16) v 54 (SD 21)) $(P<0.05)$.

290

291

Females in the classroom taught students group had an increase in potassium concentrations 292 at the end of the shift (80 (SD 47) v 110 (SD 33) mmol/l) $(P<0.05)$. Reported feelings of hunger were greater at the end of the shift for all the classroom taught students (22 (SD 19) v 50 (SD 26)), male classroom taught students (22 (SD 21) v 52 (SD 26)) and female classroom taught students (21 (SD 17) v 48 (SD 27)) $(P<0.05)$.

296

297 All reported subjective feelings in the teacher group were different between the start and end 298 of the shift. Thirst (37 (SD 24) v 56 (SD 26)), mouth dryness (39 (SD 25) v 56 (SD 27)), tiredness (51 (SD 23) v 69 (SD 22)) and hunger (15 (SD 21) v 32 (SD 23)) were significantly higher at the end of the shift. Concentration (69 (SD 22) v 51 (SD 23)) and energy (63 (SD 20) v 50 (SD 20)) levels declined throughout the shift $(P<0.05)$. In male teachers mouth dryness (30 (SD 24) v 47 (SD 28)) and hunger (9 (range 0-49) v 35 (range 5-65)) increased 
(47 (range 1-82) v 74 (range 11-93)) and tiredness (44 (SD 25) v 69 (SD 19)) increased throughout the shift whilst concentration significantly decreased (66 (SD 21) v 51 (SD 22))

$307 \quad(P<0.05)$.

309 In all security guards, concentration levels decreased throughout the shift (63 (SD 20) v 50

310 (SD 20)) $(P<0.05)$. Urine specific gravity (1.023 (SD 0.006) v 1.016 (SD 0.007)) and urine osmolality (754 (SD 198) v 573 (SD 230) mOsmol/kg) were lower at the end of the shift in the firefighters group $(P<0.05)$. Concentration levels in all office workers (70 (SD 18) v 49 (SD 20)) and in only male office workers (73 (SD 18) v 46 (SD 21)) were lower at the end of

314 the shift $(P<0.05)$. Catering staff reported greater levels of tiredness at the end of the shift

315 (29 (SD 23) v 45 (SD 25)). Male catering staff experienced greater feelings of thirst (63 (SD 20) $v 50$ (SD 20)) and mouth dryness (58 (SD 8) $v 19$ (SD 9)) at the start of the shift $(P<0.05)$.

Reported water intake

Males reported more water consumption compared with females during the monitored shifts $(P<0.0001)$. Males reported consuming 1.2 litres (range 0.0-3.3 litres) compared with 0.7 litres (range0.0-2.0 litres) for females. This was equivalent to 14 (range 0-47) $\mathrm{ml} / \mathrm{kg}$ and 10 (range 0 -32) $\mathrm{ml} / \mathrm{kg}$ for males and females respectively $(P=0.004)$. Within each group there was no difference between the water reportedly consumed by males and females (research: $1.2(0.4-3.3)$ v $0.9(0.3-1.9)$ litres, classroom: $0.7(0.0-1.1)$ v $0.5(0.0-1.4)$ litres, teachers: 0.8 $(0.4-2.5)$ v $0.6(0.0-1.2)$ litres, security: $0.9(0.3-2.0$ v $1.4(0.8-2.0)$ litres, office: 1.3 (0.5-3.0) v 0.8 (0.5-1.5) litres, catering: $1.8(0.4-2.0)$ v $0.8(0.4-1.4)$ litres for males and females respectively) $(P>0.05)$. Regardless of gender and focussing just on the work groups, the firefighters reported consuming more water than all other groups $(P<0.05)$ (Fig. 3). Reported 
water intake was weakly related to feelings of thirst at the start of the shift (positively) ( $\mathrm{r}=0.161, P=0.044$ ) but not at the end of the shift. At the end of the shift USG values were negatively related to reported water intake for the whole population ( $\mathrm{r}=0.226, P=0.005)$, males ( $\mathrm{r}=0.356, P=0.001)$ and females ( $\mathrm{r}=0.253, P=0.039$ ). A similar pattern occurred for osmolality values (whole population ( $\mathrm{r}=0.230, P=0.004$ ), males $(\mathrm{r}=0.349, P=0.001$ ) and females $(\mathrm{r}=0.272, P=0.026))$. USG and osmolality values at the start of the shift as a whole and within groups were not related to reported water intake values $(P>0.05)$. The change in USG and osmolality from the start to the end of the shift was negatively correlated with reported water intake (USG: $r=-0.325, P<0.0001$, $U_{\text {osm }}$ : $r=-0.329, P<0.0001$ ) so the larger the decrease in USG and $\mathrm{U}_{\text {osm, }}$, the greater reported water intake. When $\mathrm{U}_{\text {osm }}$ and USG decreased from the start to the end of the shift, reported water intake was greater compared to when $\mathrm{U}_{\text {osm }}$ and USG increased $(1.1(0.0-3.3)$ v $0.7(0.0-2.6)$ litres $)(P<0.05)$.

Sensations of thirst and concentration levels

117 workers reported experiencing a sensation of thirst at some point throughout the duration of the shift. 85\% ( $n$ 99) alleviated thirst by consuming a drink. The average amount of water reported that was used to satiate sensations of thirst was 0.2 (range $0.05-1.4$ ) litres. $92 \%$ of males who experienced thirst alleviated the sensation by consuming water compared with $75 \%$ of females. Concentration levels at the start and end of the shift were not related to the corresponding values for osmolality and specific gravity $(P>0.05)$. 65\% ( $n$ 101) of the workers felt that they kept themselves hydrated throughout the duration of the shift. Of those that thought they were hydrated at the end of the shift 70\% ( $n$ 71) and 68\% ( $n$ 69) had urine osmolality and urine specific gravity values respectively that were below $700 \mathrm{mOsmol} / \mathrm{kg}$ and 1.020, whilst of those that did not feel like they kept themselves hydrated 41\% (n 22) and 43\% ( $n$ 23) had osmolality and USG values respectively, not classed as euhydrated. 
Discussion

357 The purpose of the study was to examine hydration status in different working groups at the

358 start and end of a shift and examine water intake during the shift. Overall there was very

359 little difference in the hydration status parameters and reported water intake values between

360 the groups observed. Reported water intakes between groups were very similar with slight

361 differences between males and females, with males consuming more water.

362

363 Individuals in the classroom taught students group reported that the observed shift was not typical of a normal day. This was because they were in laboratory classes where drinking was prohibited unless they left the laboratory. Although not typical of a normal day but typical of one out of five working days, the group was chosen based on the laboratory classes to allow for a comparison to similar subjects in the University research/studying environment.

In general, subjects had higher values of urine specific gravity and osmolality at the start of the shift compared to the end. A large proportion of subjects (54\% at the start and $35 \%$ at the end) exhibited urine values indicating hypohydration with many (52\% of the original 54\%) remaining in a state of hypohydration at the end of the shift. Data used as markers of hydration status (USG and urine osmolality) were lower at the end the shift; however, from a physiological perspective it was difficult to determine if the difference in hydration values corresponded to a change in hydration status, particularly when using ACSM guidelines ${ }^{(6)}$ where an individual is classed as either euhydrated or not. Despite this, by collecting urines samples at least $8 \mathrm{hr}$ apart and with the reporting of water intake during the shift, a valid representation of hydration status during a typical working day was created. 
381 Females have been shown to consume less water ${ }^{(15-17)}$, confirming reported absolute and

382

383 relative water intake values in this study. This may have been due to males trying to sustain greater body water content. Kant ${ }^{(15)}$ examined 4112 individuals in North America and found no difference in plain water intake between males and females (1044 (SEM 48) v 1079 (SEM 67) g for males and females respectively; $P=0.5$ ) but females consumed significantly less water from other beverages (1783 (SEM 55) v 1298 (SEM 35) g for males and females, respectively; $P<0.0001)$. All three studies examined water intake over $24 \mathrm{~h}$ so direct comparisons may not be used but the general trends were similar. The lower reported water intake in the present study may be attributed to the lower values of USG and urine osmolality for women at the start of the shift. If males and females had both begun the shift in a similar state of hydration, reported water intake values in females may have been greater.

The firefighting group reported greater water intake during the observed shift compared with all the other groups. The firefighters are generally encouraged to drink during the shift by management and through urine colour charts in the toilets. Compared to other groups they have previously been made aware of the necessity to drink and maintain hydration status to prevent declines in cognitive and physical performance through initiatives and regular health testing. It has been shown that educating workers about dehydration, whilst assessing hydration status and implementing a water replacement program increases the likelihood of arriving at work and remaining in a euhydrated state ${ }^{(2)}$. For the firefighters the structure of their general day was dependent on emergency calls (average of three per day) and so it appeared that they would drink in anticipation of this and the possibility of wearing personal protective equipment which can often cause heat dress due to the uncompensable environment they create ${ }^{(3)}$. In contrast, the classroom taught students group reported drinking very little water. During the laboratory classes they were restricted on where they could 
406 drink and thus was reflected in the reported volume consumed and the subsequent urine 407 parameters.

408

409 Typical water intake values that have been reported in the general population from beverages 410 are approximately 1.3 litres/d from The National Diet and Food Survey ${ }^{(18)}$. This value was an 411 average per day over a seven day observation period and included alcohol consumption 412 (approximately 0.3 litres/d). In the present study, water intake was only reported during the 413 working day and so it was difficult to make direct comparison. In 2010, the European Food 414 Safety Authority outlined an adequate intake of 2.5 litres/d for males and 2.0 litres/d for 415 females from also sources of water including food ${ }^{(19)}$ whilst the Institute of Medicine had an 416 adequate intake of approximately 3.7 litres/d for males from food and beverages and 2.7 417 litres/d for females ${ }^{(20)}$. The Food Standards Agency ${ }^{(21)}$ suggested a value of 1.2 litres from beverages to prevent dehydration occurring. The recommendations vary in suggested water intake, but if the lowest value is taken, only five groups reported intake close to, or above this value in the monitored shift alone whilst the remaining two groups (classroom taught students and teachers) had the greatest barriers to water intake due to availability of water, restrictions on when and where they could drink and access to toilet facilities. Again, it must be stressed that the adequate water intakes for a day cannot be compared to the water intake during the shift as subjects were only at work for a relatively small portion of the day. However, it can provide an indication of water intake behaviours and patterns. Within the time at work it was likely that either 1 or 2 main meals, where large amounts of water, through food and accompanying drinks, would probably not be consumed.

Several subjects reported water intake over 2 litres per day with one subject in the research 430 group and two in the firefighters group reporting a water intake value of 3.3, 3.0 and 3.0 litres 
respectively throughout the shift (start $\mathrm{U}_{\text {osm }}$ of 813, 736 and $779 \mathrm{mOsmol} / \mathrm{kg}$ respectively; end $\mathrm{U}_{\text {osm }}$ of 519, 240 and $507 \mathrm{mOsmol} / \mathrm{kg}$ respectively; start USG of 1.028, 1.020 and 1.021 repectively; end USG of $1.014,1.007$ and 1.014 respectively). The firefighters group appeared most at risk from overdrinking with 14 out of 22 subjects reporting water intake over 2 litres during the shift. Despite this, urine osmolality values were, on average, above $700 \mathrm{mOsmol} / \mathrm{kg}$ at the start of the shift and this decreased slightly at the end of the shift. This, therefore suggested that either their reported water intake was adequate or that the actual volumes reported were inaccurate. When asking individuals to self report food and drink intake, often errors can occur particularly with underreporting ${ }^{(22)}$ indicating that water intake volumes in the present study might have been underreported. Only with accurate measurement of water intake through weighing of drinks and food consumed, could a more precise analysis of water intake be conducted. However, this may have altered behaviour and made participants more aware of water intake.

During day to day occupational activity thirst is an adequate stimulus to promote water replacement and help maintain hydration status ${ }^{(23)}$. Of the workers monitored, 117 (75\%) experienced a sensation of thirst at some point during the duration of the shift with $85 \%$ alleviating the sensation through a drink. These results suggest that thirst was an adequate stimulus in the present study to initiate drinking, however examining the role thirst plays maintaining hydration status is difficult because it was not known whether every bout of water intake was initiated by thirst. This becomes particularly apparent when consideration is taken of the number of subjects who were not euhydrated at the end of the shift despite sensations of thirst and alleviation with consumption of beverages. With sensations of thirst similar at the start and end of the trial, it appeared that enough water was consumed throughout the shift to maintain a certain level of thirst. 
457 Assessing a start and end urine sample provided information regarding these time points but little information regarding hydration was gathered throughout the duration of the shifts. Assumptions could have been inferred involving a direct link between start and end values, possibly suggesting that the end value arose directly from the start value. However, euhydration has been shown to follow a sinosuidal wave and fluctuate around an average value over a period of time ${ }^{(23)}$. Therefore, to determine the pattern throughout the shift it would have been advantageous to increase the frequency of sampling to a fixed number or a collection of all samples produced. The major problem with this would have been the interference with the "typical" day of the subject creating a deviation from normality and thus potentially affecting urine output and normal water intake patterns. A solution to improve this would be to test over a number of days with greater frequency of sampling, thereby allowing the subject to adjust to the method of testing.

The desire to assess hydration status and reported water intake during a typical working day resulted in limitations in the study. A compromise was reached to observe a typical day without measuring variables that, whilst potentially enhancing the results, may have impacted on normal day to day routine, thereby reducing the validity of the results. Accurate measurement of food and water intake, urine output and sweat losses plus assessment over several days may have been beneficial, however in order to provide a 'snapshot' of a typical working day without causing changes to daily routines and providing inconvenience, it was

477 felt that the current study design was most appropriate. This does have limitations in terms of 478 the interpretation of the results and conclusions reached particularly due to the accuracy of reported water intake, despite this, due to the amount of subjects recruited from each place of work, confidence can be taken in the general conclusions reached and trends identified. 
482 Conclusion

483 In conclusion a large proportion of subjects exhibited urine values indicating hypohydration 484 with many remaining in a state of hypohydration at the end of the shift. A large proportion of 485 workers (75\%) experienced a sensation of thirst throughout the shift. Access to water and 486 other beverages at work helped alleviate sensations of thirst. Increasing awareness of 487 drinking and hydration status, helped increase water consumption during the observed shift, 488 whilst males reported consuming more water per $\mathrm{kg}$ of body mass compared to females. 489 Further investigation is required to gain insight into the causes and significance of these 490 findings through blood indices and hormone analysis.

491

492

493 
494 Acknowledgements

495 The study was supported, in part, by The Coca-Cola Company.

496 
1. Bates GP \& Schneider J (2008) Hydration status and physiological workload of UAE construction workers: A prospective longitudinal observational study. J Occup Med Toxicol 3, 21.

2. Brake DJ \& Bates GP (2003) Fluid losses and hydration status of industrial workers under thermal stress working extended shifts. Occup Environ Med 60, 90-96.

3. Cheung SS \& McLellan TM (1998) Influence of hydration status and fluid replacement on

504 heat tolerance while wearing NBC protective clothing. Eur J Appl Physiol Occup Physiol 77, 505 139-148.

4. McLellan TM, Cheung SS, Latzka WA et al. (1999) Effects of dehydration,

507 hypohydration, and hyperhydration on tolerance during uncompensable heat stress. Can $J$ 508 Appl Physiol 24, 349-361.

509 5. Kenefick RW \& Sawka MN (2007) Hydration at the work site. J Am Col Nutr 26, 597S$510603 S$.

511 6. Sawka MN, Burke LM, Eichner ER et al. (2007) Exercise and fluid replacement. Med Sci 512 Sports Exerc 39, 377-390.

513 7. Armstrong LE, Maresh CM, Castellani JW et al. (1994) Urinary indexes of hydration 514 status. Int J Sport Nutr 4, 265-279.

515 8. Popowski LA, Oppliger RA, Patrick LG et al. (2001) Blood and urinary measures of 516 hydration status during progressive acute dehydration. Med Sci Sports Exerc 33, 747-753.

517 9. Shannon J, White E, Shattuck AL et al. (1996) Relationship of food groups and water 518 intake in colon cancer risk. Cancer Epidemiol Biomarkers Prev 5, 495-502.

519 10. Michaud DS, Spiegelman D, Clinton SK et al. (1999) Fluid intake and the risk of bladder cancer in men. $N$ Engl $J$ Med 340, 1390-1397. 
521 11. Lieberman HR (2007) Hydration and cognition: A critical review and recommendations

522 for future research. J Am Coll Nutr 26, 555S-561S.

523 12. Grandjean AC \& Grandjean NR (2007) Dehydration and cognitive performance. J Am

524 Coll Nutr 26, 549S-554S.

525 13. Gopinathan PM, Pichan G, Sharma VM (1988) Role of dehydration in heat stress-induced

526 variations in mental performance. Arch Environ Health 43, 15-17.

527 14. Cian C, Koulmann N, Barraud PA et al. (2000) Influence of variations in body hydration

528 on cognitive function: Effect of hyperhydration, heat stress, and exercise-induced 529 dehydration. J Psychophysiol 14, 29-36.

530 15. Kant AK, Graubard BI, Atchison EA (2009) Intakes of plain water, moisture in foods and 531 beverages, and total water in the adult US population-nutritional, meal pattern, and body 532 weight correlates: National Health and Nutrition Examination Surveys 1999-2006. Am J Clin $533 \quad$ Nutr 90, 655-663.

534 16. Mueller E, Latini J, Lux M et al. (2005) Gender differences in 24-hour urinary diaries of 535 asymptomatic North American adults. J Urol 173, 490-492.

536 17. Raman A, Schoeller DA, Subar AF et al. (2004) Water turnover in 458 American adults 537 40-79 yr of age. Am J Physiol 286, F394-F401.

538 18. Ruston D, Hoare J, Henderson L et al. (2004) National Diet and Nutrition Survey: adults 539 aged 19 to 64 years. London: The Stationery Office.

540 19. European Food Safety Authority (2010) Scientific opinion on dietary reference values for 541 water. EFSA J 8, 1459-1506.

542 20. Institute of Medicine (2004) Dietary reference intakes: Water, potassium, sodium,

543 chloride and sulfate. http://www.iom.edu/Reports/2004/Dietary-Reference-Intakes-Water-

544 Potassium-Sodium-Chloride-and-Sulfate.aspx 
545 21. Food Standards Agency (2010) Drinking enough? Eat well, be well.

546 http://www.eatwell.gov.uk/healthydiet/nutritionessentials/drinks/drinkingenough/

547 22. Mertz W, Tsui JC, Judd JT et al. (1991) What are people really eating - the relation

548 between energy-intake derived from estimated diet records and intake determined to maintain

549 body-weight. Am J Clin Nutr 54, 291-295.

550 23. Greenleaf JE (1992) Problem - Thirst, drinking behavior, and involuntary dehydration.

$551 \quad$ Med Sci Sports Exerc 24, 645-656.

552 
553 Tables

554

555 Table 1. Subjective characteristics for each group of subjects

556

\begin{tabular}{lccccccc}
\hline \multirow{2}{*}{ Group } & \multirow{2}{*}{$n$} & \multicolumn{2}{c}{ Age (years) } & \multicolumn{2}{c}{ Body mass (kg) } & \multicolumn{2}{c}{ Height (m) } \\
\cline { 2 - 8 } & & Mean & SD & Mean & SD & Mean & SD \\
\hline Research & 33 & 26 & 4 & 72.0 & 11.6 & 1.75 & 0.11 \\
Classroom taught & 24 & 23 & 1 & 71.8 & 11.2 & 1.74 & 0.08 \\
Teachers & 31 & 47 & 10 & 72.4 & 12.0 & 1.68 & 0.08 \\
Security & 15 & 44 & 9 & 97.1 & 11.3 & 1.83 & 0.09 \\
Firefighters & 22 & 38 & 8 & 85.8 & 7.9 & 1.80 & 0.05 \\
Office & 15 & 32 & 9 & 74.1 & 17.8 & 1.73 & 0.11 \\
Catering & 16 & 50 & 13 & 81.8 & 21.5 & 1.64 & 0.10 \\
\hline
\end{tabular}


558 Table 2. Environmental conditions inside and outside the place of work. Shifts column denotes number of different shifts required to collect all 559 subject group data.

\begin{tabular}{|c|c|c|c|c|c|c|c|c|c|c|c|c|c|c|c|c|c|}
\hline \multirow{4}{*}{ Group } & \multirow{4}{*}{ Shifts } & \multicolumn{16}{|c|}{ Environmental Conditions } \\
\hline & & \multicolumn{8}{|c|}{ Inside } & \multicolumn{8}{|c|}{ Outside } \\
\hline & & \multicolumn{2}{|c|}{ Start Temp $\left({ }^{\circ} \mathrm{C}\right)$} & \multicolumn{2}{|c|}{ Start RH (\%) } & \multicolumn{2}{|c|}{ End Temp $\left({ }^{\circ} \mathrm{C}\right)$} & \multicolumn{2}{|c|}{ End RH (\%) } & \multicolumn{2}{|c|}{ Start Temp $\left({ }^{\circ} \mathrm{C}\right)$} & \multicolumn{2}{|c|}{ Start RH (\%) } & \multicolumn{2}{|c|}{ End Temp $\left({ }^{\circ} \mathrm{C}\right)$} & \multicolumn{2}{|c|}{ End RH (\%) } \\
\hline & & Mean & $\mathrm{SD}$ & Mean & SD & Mean & SD & Mean & $\mathrm{SD}$ & Mean & SD & Mean & $\mathrm{SD}$ & Mean & SD & Mean & $\mathrm{SD}$ \\
\hline Research & 5 & 19.3 & 1.4 & 30.9 & 4.0 & 20.7 & 0.9 & 27.4 & 9.7 & 5.4 & 2.0 & 74.0 & 7.9 & 5.4 & 3.6 & 66.5 & 11.1 \\
\hline Classroom & 2 & 20.7 & 0.4 & 35.1 & 8.8 & 21.8 & 2.1 & 34.0 & 12.0 & 5.1 & 0.1 & 83.4 & 8.2 & 8.1 & 1.6 & 79.9 & 3.3 \\
\hline Teachers & 2 & 18.7 & 2.2 & 45.1 & 2.5 & 21.4 & 1.7 & 39.0 & 4.2 & 5.1 & 0.1 & 83.4 & 8.2 & 8.1 & 1.6 & 79.9 & 3.3 \\
\hline Security & 15 & 20.0 & 0.3 & 41.9 & 0.5 & 20.0 & 0.4 & 41.9 & 0.4 & 9.5 & 3.0 & 50.9 & 8.4 & 9.1 & 2.4 & 50.0 & 8.8 \\
\hline Firefighters & 3 & 19.7 & 1.1 & 49.8 & 5.1 & 20.4 & 1.7 & 47.9 & 1.7 & 12.8 & 5.2 & 56.5 & 4.8 & 13.1 & 5.2 & 54.3 & 0.1 \\
\hline Office & 2 & 20.6 & 3.0 & 48.4 & 6.8 & 22.0 & 0.8 & 41.4 & 0.7 & 12.5 & 1.5 & 66.3 & 13.4 & 17.8 & 3.4 & 52.2 & 9.6 \\
\hline Catering & 2 & 15.5 & 1.9 & 41.8 & 0.9 & 20.5 & 0.1 & 25.9 & 0.1 & 7.4 & 0.1 & 46.5 & 5.9 & 12.5 & 2.1 & 34.0 & 9.5 \\
\hline
\end{tabular}


569 Table 3. Start and end values of urine parameters and subjective feelings questionnaires for all subjects and male and females separately.

\begin{tabular}{|c|c|c|c|c|c|c|c|c|c|c|c|c|}
\hline & \multicolumn{4}{|c|}{ All } & \multicolumn{4}{|c|}{ Males } & \multicolumn{4}{|c|}{ Females } \\
\hline & \multicolumn{2}{|r|}{ Start } & \multicolumn{2}{|r|}{ End } & \multicolumn{2}{|r|}{ Start } & \multicolumn{2}{|r|}{ End } & \multicolumn{2}{|r|}{ Start } & \multicolumn{2}{|r|}{ End } \\
\hline & Median & Range & Median & Range & Median & Range & Median & Range & Median & Range & Median & Range \\
\hline Urine Specific Gravity & 1.021 & $1.002-1.034$ & $1.016^{*}$ & $1.002-1.033$ & 1.022 & $1.004-1.034$ & $1.018^{*}$ & $1.004-1.033$ & $1.019^{\dagger}$ & $1.002-1.029$ & $1.013^{\dagger}$ & $1.002-1.030$ \\
\hline Osmolality (mOsmol/kg) & 717 & $85-1090$ & $571 *$ & $105-1056$ & 738 & $164-1090$ & $642 *$ & $130-1056$ & $656^{\dagger}$ & $85-970$ & $461^{\dagger}$ & $105-1014$ \\
\hline Colour & 4 & $1-7$ & $3^{*}$ & $1-7$ & 4 & $1-7$ & $3^{*}$ & $1-7$ & $3^{\dagger}$ & $1-7$ & 3 & $1-6$ \\
\hline Sodium conc. (mmol/l) & 95 & $13-203$ & 90 & $14-205$ & 101 & $32-203$ & 108 & $16-205$ & $86^{\dagger}$ & $13-182$ & $76^{*}$ & $14-177$ \\
\hline Potassium conc. (mmol/l) & 95 & $11-169$ & $86^{*}$ & $16-179$ & 96 & $21-157$ & $85 *$ & $17-179$ & 93 & $11-169$ & 87 & $16-159$ \\
\hline Thirst & 49 & $0-100$ & 49 & $2-100$ & 52 & $0-100$ & 48 & $2-89$ & $38^{\dagger}$ & $0-100$ & $57 *$ & $2-100$ \\
\hline Mouth Dryness & 46 & $0-100$ & 50 & $0-93$ & 50 & $0-100$ & 50 & $2-86$ & 40 & $0-84$ & 48 & $0-93$ \\
\hline Tiredness & 49 & $0-100$ & $63^{*}$ & $0-100$ & 50 & $0-100$ & $63 *$ & $7-100$ & 47 & $0-98$ & $62 *$ & $0-100$ \\
\hline Hunger & 19 & $0-96$ & $30 *$ & $0-94$ & 24 & $0-85$ & $35^{*}$ & $0-80$ & $13^{\dagger}$ & $0-96$ & $20^{* \dagger}$ & $0-94$ \\
\hline Concentration & 70 & $2-100$ & $62 *$ & 5-98 & 68 & $7-100$ & $63 *$ & 6-95 & 70 & 2-95 & 61 & $8-98$ \\
\hline Energy & 63 & $0-100$ & $53 *$ & $0-92$ & 63 & $0-100$ & $55^{*}$ & $0-91$ & 63 & $1-100$ & $55^{*}$ & $11-92$ \\
\hline
\end{tabular}


572 Table 4. Percentage of subjects in each group who were hypohydrated at the start and end of 573 the shift using urine values of greater than 1.020 (USG) and $700 \mathrm{mosmol} / \mathrm{kg}$ (osmolality) ${ }^{(6)}$ 574

\begin{tabular}{|c|c|c|c|c|c|c|c|c|}
\hline \multirow{3}{*}{ Group } & & \multirow[b]{3}{*}{$n$} & \multicolumn{6}{|c|}{ Subjects hypohydrated (\%) } \\
\hline & & & \multicolumn{3}{|c|}{ Osmolality (mOsmol/kg) } & \multicolumn{3}{|c|}{ Urine Specific Gravity } \\
\hline & & & Start & End & Both & Start & End & Both \\
\hline \multirow[t]{3}{*}{ All } & & 156 & 54 & 35 & 26 & 53 & 33 & 29 \\
\hline & Males & 89 & 64 & 40 & 33 & 63 & 37 & 35 \\
\hline & Females & 67 & 42 & 28 & 19 & 40 & 27 & 21 \\
\hline \multirow[t]{3}{*}{ Research } & & 33 & 73 & 33 & 27 & 70 & 27 & 30 \\
\hline & Males & 22 & 77 & 36 & 32 & 73 & 32 & 36 \\
\hline & Females & 11 & 64 & 27 & 18 & 64 & 18 & 18 \\
\hline Classroom & & 24 & 46 & 54 & 33 & 42 & 50 & 38 \\
\hline \multirow{2}{*}{ taught students } & Males & 12 & 50 & 58 & 33 & 42 & 50 & 42 \\
\hline & Females & 12 & 42 & 50 & 33 & 42 & 50 & 33 \\
\hline \multirow[t]{3}{*}{ Teachers } & & 31 & 39 & 23 & 16 & 39 & 23 & 13 \\
\hline & Males & 11 & 45 & 27 & 18 & 33 & 17 & 18 \\
\hline & Females & 20 & 35 & 20 & 10 & 30 & 20 & 10 \\
\hline \multirow[t]{3}{*}{ Security } & & 15 & 67 & 53 & 40 & 60 & 53 & 47 \\
\hline & Males & 11 & 73 & 55 & 45 & 73 & 55 & 45 \\
\hline & Females & 4 & 50 & 50 & 25 & 25 & 50 & 50 \\
\hline \multirow[t]{3}{*}{ Fire } & & 22 & 73 & 36 & 23 & 73 & 36 & 32 \\
\hline & Males & 22 & 73 & 36 & 23 & 73 & 36 & 32 \\
\hline & Females & 0 & - & - & - & - & - & - \\
\hline \multirow[t]{3}{*}{ Office } & & 15 & 40 & 13 & 13 & 47 & 20 & 13 \\
\hline & Males & 8 & 38 & 25 & 25 & 38 & 38 & 25 \\
\hline & Females & 7 & 43 & 0 & 0 & 57 & 0 & 0 \\
\hline \multirow[t]{3}{*}{ Catering } & & 16 & 38 & 38 & 38 & 38 & 38 & 38 \\
\hline & Males & 3 & 67 & 67 & 67 & 67 & 67 & 67 \\
\hline & Females & 13 & 31 & 31 & 31 & 31 & 31 & 31 \\
\hline
\end{tabular}


$576 \quad$ Figures

$577 \quad$ Figure 1

578

579

580

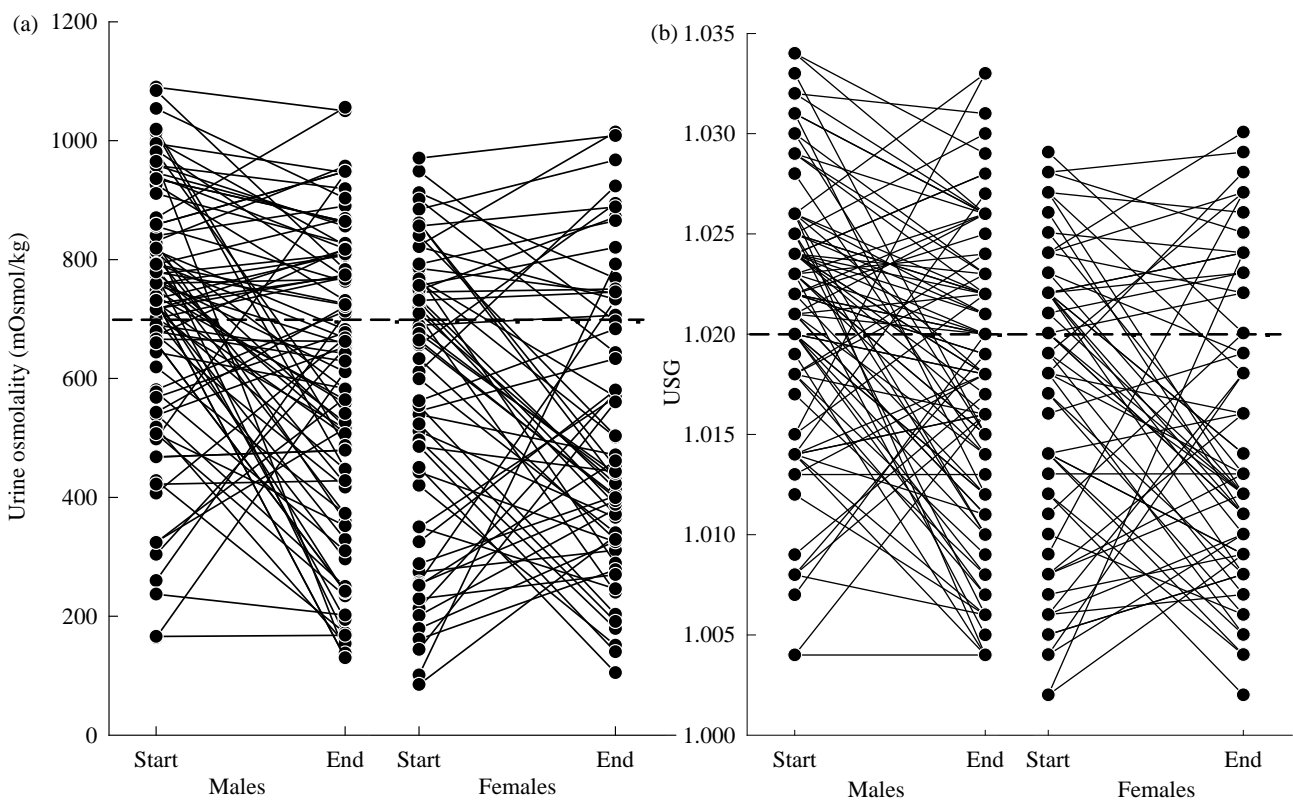


581 Figure 2

582

583

584
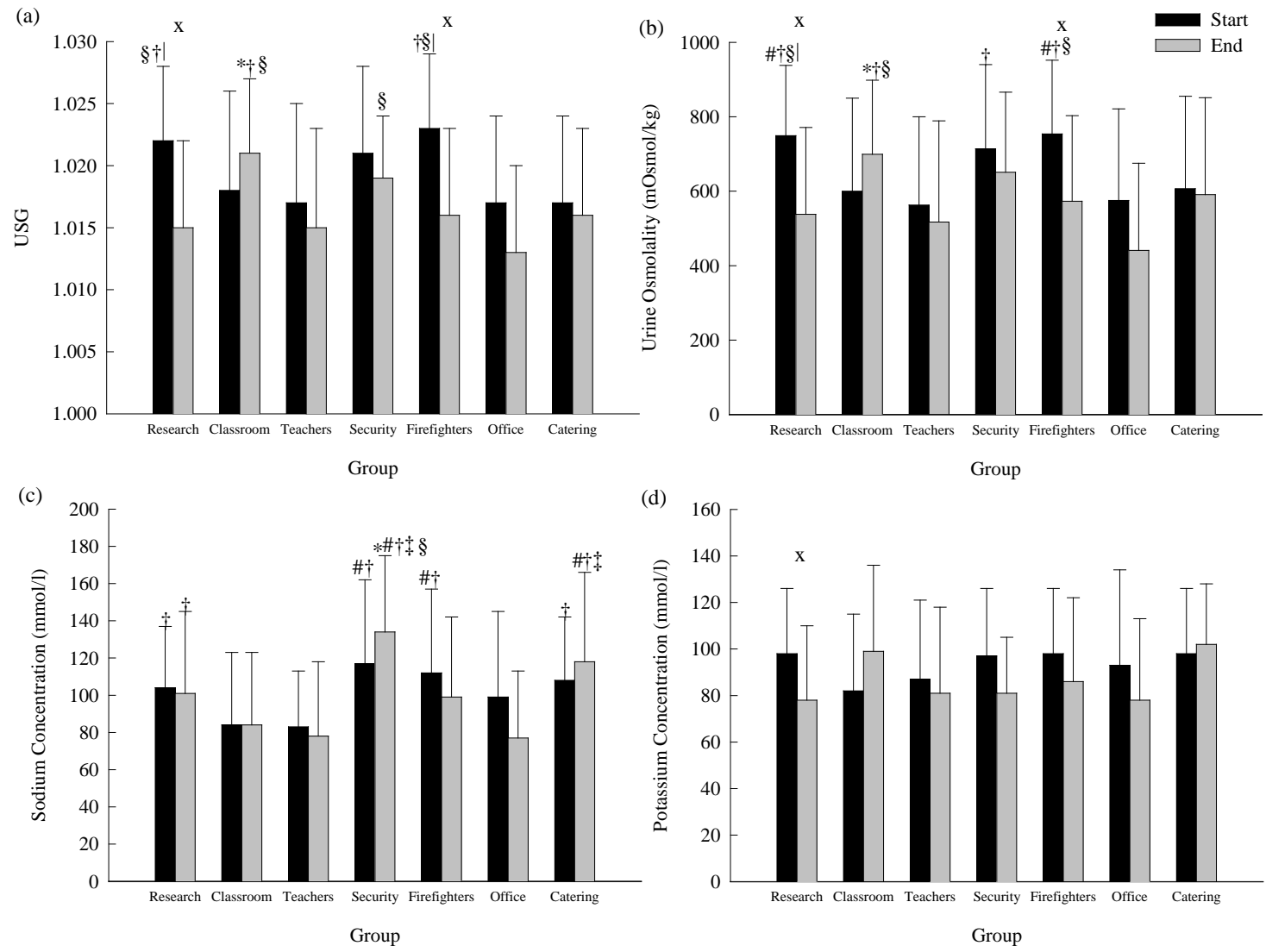

585

586

587 
$588 \quad$ Figure 3

589

590

591

592

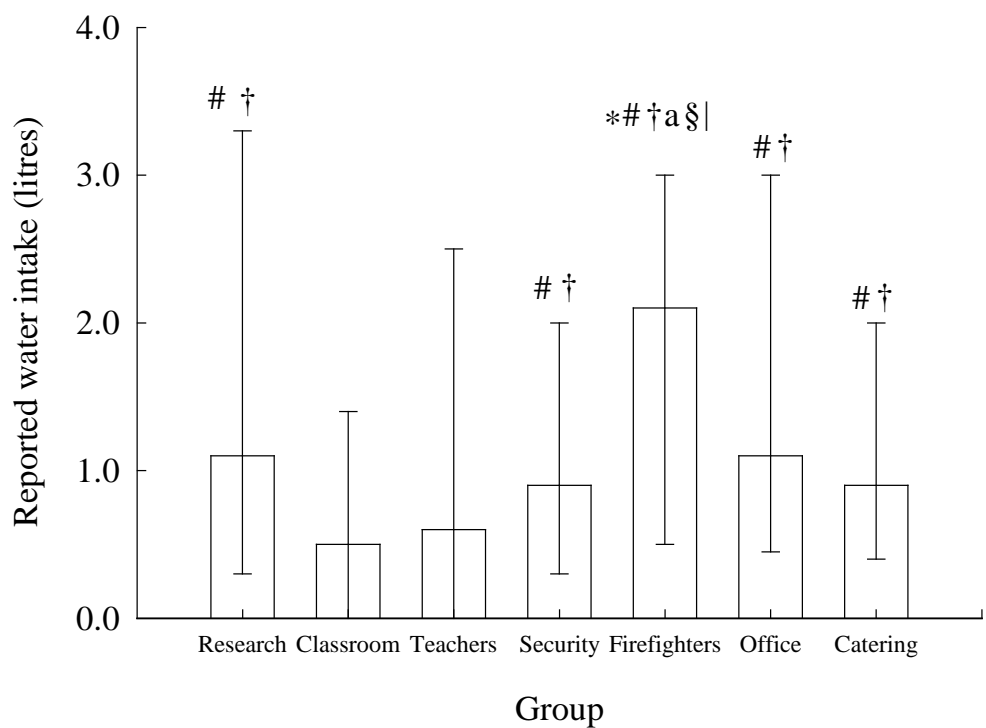


593 Legends

594 List of figures

595 Figure 1. Start and end (a) osmolality (mOsmol/kg) and (b) urine specific gravity for males 596 and females. - - - represents euhydration values of less than 1.020 and $700 \mathrm{mOsmol} / \mathrm{kg}^{(6)}$

597 Figure 2. USG (a), osmolality (mOsmol/kg) (b), urine sodium (c) and potassium 598 concentrations (mmol/l) (d) at the start (black) and end (grey) of the shift (mean \pm SD). * 599 denotes greater than research group, \# denotes greater than classroom taught students, $\dagger$ 600 denotes greater than teachers, $\ddagger$ denotes greater than firefighters, $\S$ denotes greater than office 601 and $\mid$ denotes greater than catering $(P<0.05) . x$ denotes difference between start and end 602 values $(P<0.05)$

603 Figure 3. Reported water intakes for each group during the shift (median (range)). * greater 604 than research group, \# greater than classroom taught students, $\dagger$ greater than teachers, ${ }^{a}$ 605 greater than security, $\S$ greater than office and $\mid$ greater than catering $(P<0.05)$ 